\title{
Acute Intestinal Ischemia in a Patient with COVID-19 Infection
}

\author{
Balraj Singh, Ashesha Mechineni ${ }^{1}$, Parminder Kaur ${ }^{2}$, Nora Ajdir ${ }^{1}$, Michael Maroules, Fayez Shamoon ${ }^{2}$ \\ and Mahesh Bikkina ${ }^{2}$ \\ Departments of Hematology \& Oncology, Internal Medicine', Cardiology², Saint Joseph's University Medical Center, Paterson, \\ USA
}

The World Health Organization has declared novel coronavirus disease 2019 (COVID-19) a global public health emergency. Although respiratory symptoms predominate in COVID-19, thrombosis can occur in patients with COVID-19. This paper reports a case of an 82-year-old female with a prior medical history of hypertension, diabetes presenting with fever and cough, and was diagnosed with COVID-19. The patient subsequently developed progressively worsening of abdominal distention, tenderness, and underwent emergent laparotomy. She was found to have a gangrenous colon. This case adds to the limited literature regarding the extrapulmonary complications of COVID-19. (Korean J Gastroenterol 2020;76:164-166)

Key Words: COVID-19; Arterial thrombosis; Severe acute respiratory syndrome coronavirus 2; Mesenteric ischemia; Ischemic colitis

\section{INTRODUCTION}

Coronavirus disease 2019 (COVID-19) is a viral infection that originated from Wuhan, China. The disease is caused by a novel enveloped single-stranded RNA beta coronavirus, known as the severe acute respiratory syndrome coronavirus 2. The World Health Organization declared COVID-19 a global pandemic on March 11th, 2020. This new disease has posed a myriad of challenges to the scientific community. The most commonly reported clinical manifestations of COVID-19 are fever, myalgia, cough, dyspnea, and less frequently, headache, diarrhea, nausea, and vomiting. ${ }^{1}$ The limitations placed by the current ongoing pandemic resulted in clinicians relying on the anecdotal literature and observational studies to learn about the various manifestations of this condition. Lately, there have been reports of thromboembolic events in this group of patients leading to a whole spectrum of clinical presentations. ${ }^{2,3}$ This paper reports a case of an 82-year-old female with a prior medical history of hypertension who presented with fever and cough and was diagnosed with COVID-19. She subsequently developed abdominal distention, tenderness, and underwent emergent laparotomy and was found to have a gangrenous colon.

\section{CASE REPORT}

We report an 82-year-old female patient with a pertinent history of hypertension, non-insulin-dependent diabetes mellitus, who presented to the emergency room with a 2 week history of persistent fever, shortness of breath, and cough. She was diagnosed with COVID-19 viral pneumonia and started on empiric therapy with hydroxychloroquine and azithromycin. Her oxygen supplementation requirement increased progressively through the hospital stay, resulting in ventilatordependent respiratory failure on day 10 . The patient remained hemodynamically stable through the transition and, at no point,

Received May 22, 2020. Revised July 1, 2020. Accepted July 6, 2020.

(C) This is an open access article distributed under the terms of the Creative Commons Attribution Non-Commercial License (http://creativecommons.org/licenses/ by-nc/4.0) which permits unrestricted non-commercial use, distribution, and reproduction in any medium, provided the original work is properly cited. Copyright (c) 2020. Korean Society of Gastroenterology.

Correspondence to: Balraj Singh, Department of Hematology \& Oncology, Saint Joseph's University Medical Center, 703 Main Street, Paterson, NJ 07503, USA. Tel: +1-9736894979, Fax: +1-9737542444, E-mail: bsriar9@gmail.com, ORCID: https://orcid.org/0000-0001-7986-6031

Financial support: None. Conflict of interest: None. 
required vasopressor support. She was given a deep venous thrombosis prophylaxis dose of heparin. She was noted as having severe diffuse abdominal distension and tenderness on day 18 of her hospital stay and was evaluated for bowel perforation. The laboratory evaluation revealed the following: hemoglobin, $10.3 \mathrm{~g} / \mathrm{dL}$ (reference: $12-16 \mathrm{~g} / \mathrm{dL}$ ), hematocrit $34 \%$ (reference: 36-46\%), white blood cells $22.8 \mathrm{k} / \mathrm{mm}^{3}$ (reference: $4.5-11 \mathrm{k} / \mathrm{mm}^{3}$ ), platelets 146 (reference: $140-440$ $\mathrm{K} / \mathrm{mm}^{3}$ ), potassium of $4.4 \mathrm{meq} / \mathrm{L}$ (reference: $3.5-5 \mathrm{meq} / \mathrm{L}$ ), blood glucose 152 mg/dL (reference: 70-105 mg/dL), creatinine of $4 \mathrm{mg} / \mathrm{dL}$ (reference: 0.6-1.30 mg/dL), blood urea nitrogen $140 \mathrm{mg} / \mathrm{dL}$ (reference: $7-23 \mathrm{mg} / \mathrm{dL}$ ), lactic acid $2.5 \mathrm{mmol} / \mathrm{L}$ (reference: $0.5-2.2 \mathrm{mmol} / \mathrm{L}$ ), troponin of $0.074 \mathrm{ng} / \mathrm{mL}$ (reference: less than $0.03 \mathrm{ng} / \mathrm{mL}$ ), D-dimer 1.3 (reference: less than 0.5), prothrombin time $15.3 \mathrm{sec}$ (reference: 12.2-14.9 sec), INR-1.2 (reference: less than 1), partial thromboplastin time -43 sec (reference: 21.3-35.1 sec); fibrinogen $797 \mathrm{mg} / \mathrm{dL}$ (reference: $183-503 \mathrm{mg} / \mathrm{dL}$ ), lactate dehydrogenase $-333 \mathrm{U} / \mathrm{L}$ (reference: 140-271 U/L); C-reactive protein $-308 \mathrm{mg} / \mathrm{L}$ (reference: less than $10 \mathrm{mg} / \mathrm{L}$ ), ferritin $136 \mathrm{ng} / \mathrm{mL}$ (reference: 12-300 ng/mL), procalcitonin $5.8 \mathrm{ng} / \mathrm{mL}$ (reference: less than $2 \mathrm{ng} / \mathrm{mL}$ ), interleukin-6 $44 \mathrm{pg} / \mathrm{mL}$ (reference:0-15.5 pg/mL), aspartate transaminase $33 \mathrm{U} / \mathrm{L}$ (reference: 13-39 U/L); calcium $7.3 \mathrm{mg} / \mathrm{dL}$ (reference: 8.6-10.3 mg/dL); albumin 2.9

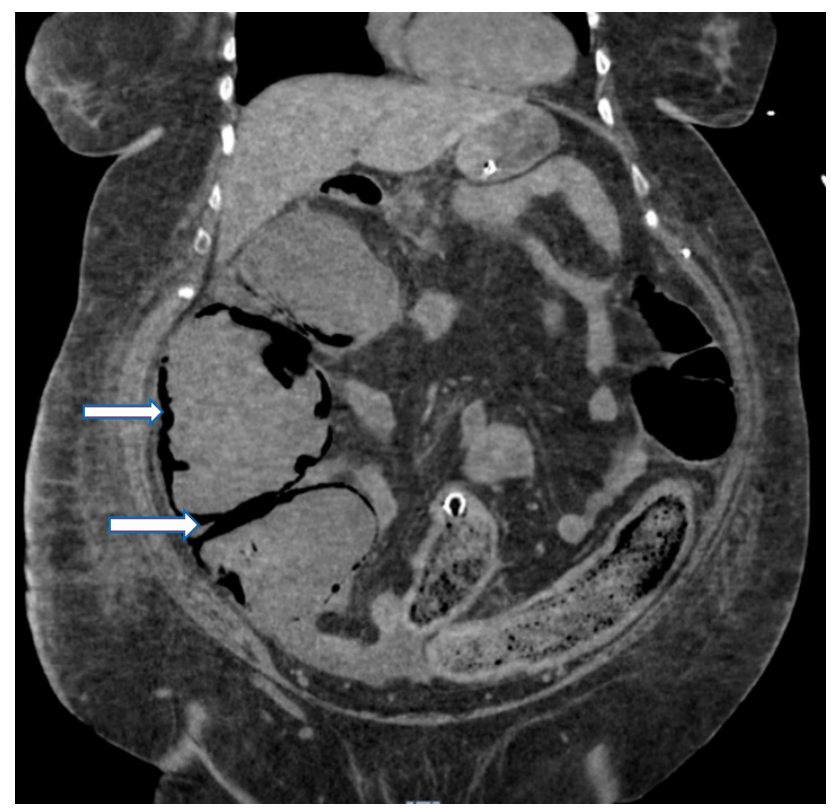

Fig. 1. Computed tomography of the abdomen showing moderate distention of the colon with significant pneumatosis intestinalis (presence of gas within the wall of the intestine-arrow) involving the ascending colon and the cecum. $\mathrm{mg} / \mathrm{dL}$ (reference: 3.5-5.0 mg/dL).

CT of the abdomen without intravenous contrast revealed pneumatosis intestinalis affecting the ascending colon and cecum (Fig. 1). The mesenteric vessels were not visualized due to a lack of intravenous contrast in the initial imaging. On the other hand, the CT angiogram of the abdomen and pelvis with intravenous contrast was performed later, showing no evidence of atherosclerosis. Emergency surgery was performed. With family consent, the patient was taken to the operating room and was found to have a gangrenous ascending colon and markedly distended colon from the cecum to rectosigmoid junction. The patient underwent ileostomy. The patient was started on a therapeutic dose of heparin for systemic anticoagulation peri- and postoperatively. The pathology revealed extensive areas of ischemic changes, including extensive mucosal, submucosal necrosis, microvascular thrombosis, focal hemorrhages, and no perforation (Fig. 2). The patient was later extubated and recovered well after surgery. The patient on the day 30 follow up was stable on room air and tolerating her diet.

\section{DISCUSSION}

The COVID-19 pandemic is a fast-evolving situation, so re-

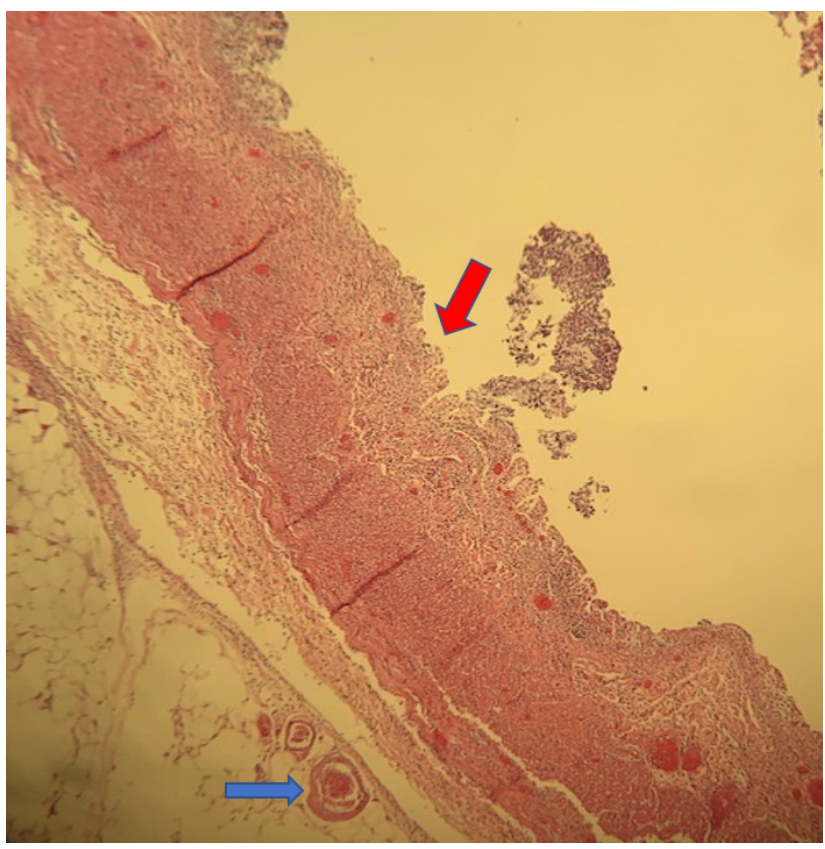

Fig. 2. Pathological findings $(H \& E, \times 20)$ : colon segment showing extensive mucosal, submucosal necrosis (upper arrow), and microthrombi (lower arrow). 
ports of unique aspects of this infection are essential to aid clinicians in managing these patients. Thrombotic complications associated with COVID-19 have been described; these have mainly included venous thromboembolic events. Arterial thrombosis has been reported, but the prevalence is not known. Multiple case reports of acute limb ischemia have been described pointing towards the hypercoagulable nature of this disease. ${ }^{2,3}$ This paper reports a case of acute mesenteric ischemia (AMI) in a COVID-19 patient.

$\mathrm{AMI}$ is a rare abdominal emergency that usually requires a wide intestinal resection. A prompt diagnosis is essential for successful treatment. The precise pathological mechanism leading to the complication of AMI in COVID-19 is not known. COVID-19-related hypercoagulability is likely a multifactorialdirect viral infection of the endothelial cell leading to diffuse endothelial inflammation, increased procoagulant factors like factor VIII, von Willebrand factor, fibrinogen, and high inflammatory state associated with the cytokine storm leading to coagulation and fibrinolysis activation. ${ }^{4,5}$ Additional explanations for the hypercoagulability may be the presence of large numbers of prothrombotic circulating microvesicles, which are cytoplasmic microparticles stemming from platelets or monocytes and neutrophil extracellular traps released from activated neutrophils that constitute a mixture of nucleic DNA, histones and nucleosomes. ${ }^{5}$ Another possible mechanism includes direct bowel damage by the novel beta-coronavirus given expression of angiotensin-converting enzyme 2 on enterocytes of the small bowel, the target receptor for SAR-CoV-2. ${ }^{6}$ In the present patient, the COVID-19-related inflammatory markers (fibrinogen 797 $\mathrm{mg} / \mathrm{dL}$, C-reactive protein $308 \mathrm{mg} / \mathrm{L}$, interleukin-6 44 pg/mL and procalcitonin $5.8 \mathrm{ng} / \mathrm{mL}$ ) were high, likely leading to microvascular thrombosis. Bianco et al. ${ }^{7}$ reported another case of acute intestinal ischemia in a patient with COVID-19.

Delays in the diagnosis of AMl are common and associated with high rates of morbidity and mortality. Prompt diagnosis requires a high index of suspicion and early contrast CT imaging. Treatment of this condition is focused on gastro- intestinal decompression, fluid resuscitation, hemodynamic support, surgical resection of the necrotic bowel, and restoration of blood flow to the ischemic intestine. ${ }^{8}$ The diagnosis of an ischemic bowel should be one of the top differentials in critically ill patients when clinical symptoms are suggestive. This case supports the hypercoagulability state in COVID-19 patients. Initially considered as a respiratory illness, COVID-19 infections in select individuals can cause disseminated coagulopathy, multi-organ failure, and mortality. This paper reports a case where the sequelae of coagulopathy led to significant comorbidity in an elderly patient. The case adds to the literature regarding the extrapulmonary complications of COVID-19. Health care providers should have a high index of suspicion regarding life-threatening complications of COVID-19 so that timely intervention can be done.

\section{REFERENCES}

1. Guan WJ, Ni ZY, Hu Y, et al. Clinical characteristics of coronavirus disease 2019 in China. N Engl J Med 2020;382:1708-1720.

2. Kaur $P$, Qaqa $F$, Ramahi $A$, et al. Acute upper limb ischemia in a patient with COVID-19. Hematol Oncol Stem Cell Ther 2020 May 13. [Epub ahead of print]

3. Kaur P, Posimreddy S, Singh B, et al. COVID-19 presenting as acute limb ischaemia. Eur J Case Rep Intern Med 2020 May 19. [Epub ahead of print]

4. Varga Z, Flammer AJ, Steiger P, et al. Endothelial cell infection and endotheliitis in COVID-19. Lancet 2020;395:1417-1418.

5. Panigada M, Bottino N, Tagliabue P, et al. Hypercoagulability of COVID-19 patients in intensive care unit: a report of thromboelastography findings and other parameters of hemostasis. J Thromb Haemost 2020;18:1738-1742.

6. Parry AH, Wani AH, Yaseen M. Acute mesenteric ischemia in severe coronavirus-19 (COVID-19): possible mechanisms and diagnostic pathway. Acad Radiol 2020;27:1190.

7. Bianco F, Ranieri AJ, Paterniti G, Pata F, Gallo G. Acute intestinal ischemia in a patient with COVID-19. Tech Coloproctol 2020 Jun 6. [Epub ahead of print]

8. Bala M, Kashuk J, Moore EE, et al. Acute mesenteric ischemia: guidelines of the World Society of Emergency Surgery. World J Emerg Surg 2017;12:38. 